\title{
Formação interdisciplinar em saúde e práticas coletivas
}

\author{
Interdisciplinary education in health and collective practices
}

Adriana Barin de Azevedo', Luciane Maria Pezzato², Rosilda Mendes ${ }^{\mathbf{3}}$

RESUMO A Universidade Federal de São Paulo, campus Baixada Santista, acompanhando os movimentos de mudança na formação em saúde no País, propõe, em seu Projeto Político Pedagógico, um desenho curricular que propicia a formação integrada entre as diferentes áreas profissionais. Este artigo objetiva investigar alguns aspectos do trabalho interdisciplinar, interprofissional e comum do processo formativo, colocando em análise um dos módulos do eixo comum chamado 'Trabalho em equipe e práticas coletivas'. O desafio destacado é o de não burocratizar as ações e o modo de pensar a saúde, para que a experiência seja produtora de sujeitos eticamente compromissados com a vida.

PALAVRAS-CHAVE Educação. Educação superior. Educação em saúde. Promoção da saúde.

ABSTRACT The Federal University of São Paulo, Baixada Santista campus, accompanying the movements of change in the education in health in the Country, proposes, in its Pedagogical Policy Project, a curricular design that provides the integrated education between the different professional areas. This article aims to investigate some aspects of the interdisciplinary, interprofessional and common work of the formative process, analyzing one of the modules of the common axis called 'Team work and collective practices'. The emphasized challenge is not to bureaucratize actions and the way of thinking health, for this experience to be producer of subjects ethically committed to life.

KEYWORDS Education. Higher education. Health education. Health promotion.

1 Universidade Federal de São Paulo (Unifesp) Santos (SP), Brasil. adribarin@gmail.com

2 Universidade Federal de São Paulo (Unifesp) Santos (SP), Brasil. lucianepezzato@gmail.com

3 Universidade Federal de São Paulo (Unifesp) Santos (SP), Brasil.

rosilda.mendes3@gmail.com 


\section{Introdução}

No bojo da discussão sobre os movimentos de mudança na formação em saúde no País, alguns cursos de graduação desta área - como os da Universidade Federal de São Paulo (Unifesp), campus Baixada Santista - incorporaram, em seus Projetos Políticos Pedagógicos (PPP), a partir de 2006, um desenho curricular que propicia a formação integrada entre as diferentes áreas profissionais: psicologia, terapia ocupacional, educação física, nutrição, fisioterapia e serviço social. Neste desenho, busca-se dar centralidade à interdisciplinaridade, à interprofissionalidade e à formação em 'comum' das profissões de saúde, assim como a defesa de uma concepção de cuidado integral, a partir de alianças de saberes e práticas de saúde geradas por meio de processos dialógicos e solidários.

Os seis cursos têm um desenho curricular estruturado em quatro eixos de formação, que perpassam os anos de graduação. Um deles, 'Aproximação a uma prática específica em saúde', é direcionado aos estudantes de cada área profissional. Os demais eixos são comuns: 'Trabalho em saúde'; 'O ser humano em sua dimensão biológica'; e 'O ser humano e sua inserção social'. O eixo 'Trabalho em saúde' (TS) percorre os três primeiros anos de graduação e visa possibilitar aos estudantes uma visão abrangente do processo saúde/ doença/cuidado e do Sistema Único de Saúde (SUS). Uma de suas características fundamentais é a garantia de um 'trabalho vivo em ato', coletivo, que se realiza no momento do encontro entre sujeitos, que envolve escuta, disponibilidade, sensibilidade, implicação, confiança (FEUERWERKER; CAPOZZOLO, 2013).

$O$ presente artigo, quando se refere à dimensão coletiva do trabalho em saúde, reporta-se, comumente, às noções de interdisciplinaridade e de interprofissionalidade. São conceitos que se constituem a partir da crítica ao conhecimento contemporâneo, enraizado no pensamento moderno, de base iluminista, que separou o saber em partes especializadas e foi tomado como referência para organizar o mundo em todos os campos, inclusive no trabalho e na saúde. Ainda que esses conceitos estejam cercados de controvérsias, ao mesmo tempo, têm sido admitidos como possibilidades para postular uma nova prática na formação dos profissionais de saúde (FURTADO, 2007; FEUERWERKER; CAPOZZOLO, 2013; HENZ, ET AL., 2013).

A fim de ampliar ainda mais esta questão, o tema do comum se soma ao debate da interdisciplinaridade e da interprofissionalidade. Em um processo formativo, criar condições de convivência contínua entre áreas diferentes produz um deslocamento na formação de origem de cada uma dessas áreas, o que gera uma partilha, um espaço de contaminação e composição, a partir de situações concretas das quais elas participam. Segundo Kastrup e Passos (2014, P. 20-21),

o conceito de comum se define por sua consistência experiencial e concreta e constitui um desafio a ser permanentemente enfrentado, [...] acompanhando as práticas concretas que 'comunam', [...] e, consequentemente, criam o efeito de pertencimento.

O 'comum', como um desafio permanente, partilhado pela experiência, implica em um pertencimento, mas não no sentido de estabelecer uma comunidade de iguais. Muitas vezes, há uma expectativa a respeito do ato de tornar os discursos entre as áreas mais homogêneos, de que isto poderia reduzir os embates e as experiências de tensão vividas entre tais áreas. O crescente isolamento das especialidades profissionais tem impedido situações de diálogo e, por isso, a busca por uma experiência comum se faz necessária. No entanto, esta proposta de aproximação precisa ocorrer a partir da diferença entre as áreas, garantindo, assim, que cada uma aprenda com a outra.

Portanto, pensar que o comum homogeneizaria as práticas, abolindo a singularidade das profissões, é pautar-se em uma falsa 
premissa. Trata-se, segundo Nancy (2000), de uma concepção transcendentalizada do termo comum, baseada na nostalgia de uma comunidade, marcada por uma relação de convivialidade que teria se perdido. $\mathrm{O}$ imaginário de que esta união estaria pautada em uma mesma crença, em um mesmo modo de pensar, atravessa as relações acadêmicas e as profissões de saúde, as quais veem as práticas coletivas como negações de suas particularidades, daquilo que lhes define como profissões.

Nessa concepção de comum aqui buscada, na formação para o trabalho em saúde, aposta-se em uma experiência de reinvenção contínua das práticas, a partir das diferentes maneiras de estabelecer alianças entre as áreas profissionais, dentro e fora da universidade, com pactuações e repactuações, a cada semestre.

Caberia indagar, no entanto, se os processos formativos em curso podem ser capazes de criar outro modo de pensar e agir, de forma a colocar em questão o individualismo, oriundo de uma ótica fragmentadora, hegemônica, na formação em saúde, uma vez que exigem um enorme esforço coletivo de construção de capacidades e de aprendizagens.

Este artigo propõe-se a investigar alguns aspectos do trabalho interdisciplinar, interprofissional e comum do processo formativo, colocando em análise um dos módulos do eixo comum 'Trabalho em saúde', denominado 'Trabalho em equipe e práticas coletivas'. O mesmo será apresentado através das reflexões do corpo docente, da análise dos textos de apoio, bem como das intencionalidades teórico-metodológicas e do material de avaliação dos estudantes quanto às experiências neste módulo.

Embora este artigo possa apresentar limitações em relação às generalizações e a outras experiências de ensino, já que se trata da discussão de apenas um dos módulos do currículo de formação em saúde, ele tem o mérito de captar as nuances e capilaridades de um projeto de formação contra-hegemônico e inovador.

Este trabalho deter-se-á, então, na apresentação do módulo, procedendo a uma releitura dos textos de apoio deste, de forma a contextualizar as intencionalidades teórico-metodológicas do percurso formativo, que será apresentado no item 'Pressupostos para práticas coletivas em saúde’. Além disso, far-se-á, também, a análise das avaliações que acompanharam os relatos dos estudantes quanto aos aprendizados e/ou dificuldades vivenciadas nesse módulo, que serão expostas no item 'Os efeitos da formação comum'.

\section{Pressupostos para práticas coletivas em saúde}

Este é um dos cinco módulos oferecidos no quarto semestre, e previsto na formação dos seis cursos de graduação do eixo TS, que busca fortalecer o aprendizado do trabalho comum realizado com grupos interdisciplinares.

Com o intuito de constituir equipes interdisciplinares de estudantes e possibilitar o exercício de práticas comuns, duas dimensões são priorizadas: o trabalho em equipe; e a ação coletiva na comunidade e/ou com grupos populacionais. A primeira dimensão considera que a equipe é um tecido de relações de saberes e poderes, e inclui pessoas com formações e histórias diferentes, que se encontram para cuidar de pessoas com necessidades de saúde singulares e formular projetos de promoção de vida (BRASIL, 2005). Para dar conta desta dimensão, aqui são abordados temas como: o trabalho em equipe; o trabalho em coletivos; a construção do trabalho comum; o protagonismo; e a ética. A segunda dimensão abarca conceitos e perspectivas da promoção da saúde, da educação dialógica, libertária e problematizadora, a fim de reforçar práticas coletivas com enfoque na educação para a autonomia (FREIRE, 2008; CZERESNIA, 2003; MENDES; FERNANDEZ; SACARDO, 2016).

Cerca de 200 estudantes, dos seis cursos de graduação, são distribuídos em turmas 
de 10-12 estudantes, assumidas por docentes das diferentes áreas de formação do campus. Para que este desenho seja possível, constitui-se um grupo de 20 docentes, sendo alguns da área de saúde coletiva e outros das áreas específicas. De um total de 80 horas previstas para o módulo, 52 são teóricas e 28 práticas, ou seja, a construção de conhecimento acontece nesta conexão entre teoria e prática. É neste contexto de aprendizado contínuo entre docentes, estudantes-docentes e população-estudantes-docentes que se desenrola a experiência de grupo. Este deslocamento de estudantes e docentes, do espaço da universidade em direção ao território existencial dos grupos populacionais, permite conhecer as condições de vida e a complexidade das questões de saúde de cada grupo acompanhado. A partir destas aproximações, os estudantes elaboram e implementam atividades, que têm o objetivo de criar um espaço de escuta, de cuidado e de promoção de saúde, incluindo, também, o grupo populacional na decisão do que será realizado.

No campo da saúde, espera-se que o trabalho aconteça a partir do diálogo entre as diferentes áreas, pactuando ações comuns para o cuidado do outro. No entanto, estas ações nem sempre são comuns, ao contrário, elas são isoladas quando cada área se ocupa apenas com o que se refere ao seu saber específico, sem considerar a complexidade das condições de vida e saúde da população atendida. Neste sentido, a aposta do presente trabalho no módulo é colocar estas questões em análise e refletir, coletivamente, se é possível, no processo formativo, trabalhar as dificuldades grupais próprias às equipes profissionais. Para isto, pergunta-se: De que maneira é possível trabalhar o processo da equipe, as práticas coletivas, discutindo questões de promoção da saúde e de educação dialógica, com enfoque na autonomia de estudantes e grupos populacionais acompanhados?

A dimensão coletiva do trabalho em saúde tem sido muito valorizada ao colocar em questão o caráter individualista, apriorístico e disciplinar prevalente nas práticas de saúde. Tem, portanto, orientado as principais propostas de renovação de conceitos e práticas, na atualidade, ao reconhecer que, para abordar a complexidade do trabalho em saúde, faz-se necessário: permitir distintos olhares, saberes e fazeres; e cooperar com outros em prol de uma finalidade comum - o cuidado em saúde (BRASIL, 2005; AYRES, 2001). Nesse módulo, tal desafio é colocado na medida em que os estudantes aprendem a criar estratégias de composição entre si e com um grupo populacional.

$\mathrm{Na}$ perspectiva da análise institucional, este grupo constituído por estudantes e/ ou pela população, é atravessado por muitas instituições. Como afirma Lourau (1993, P. 29), "os grupos são suscetíveis a vários níveis de análise", lembrando que as instituições geram conflitos entre as forças conservadoras do instituído e as revolucionárias do instituinte, sendo ambas, partes integrantes da realidade dos grupos e dos serviços. Neste sentido, ao se tomar o grupo como um dispositivo que possibilita a fala, o encontro entre os integrantes, está-se criando movimento, como diria Barros (2007, P. 268), colocando "algo em funcionamento". Com isso, o grupo não é uma técnica, mas um dispositivo de intervenção, que permite colocar em análise a relação entre todos os seus integrantes, "sob a forma de uma discussão coletiva” (LOURAU, 1993, P. 30). É, portanto, aquilo que atravessa o grupo, que faz aparecer a multiplicidade, as diferenças.

Diversas teorias sobre grupos - ou 'escolas', como alguns autores preferem denominar - surgem no início do século XX, dentro de diferentes territórios epistemológicos. Entre elas, podem ser citadas as de Jacob Levy Moreno, Kurt Lewin, Taylor, Elton Mayo, Pichón Rivière, Foulkes, Wilfred R. Bion, e os mais contemporâneos George Lapassade e Félix Guattari. No entanto, não é a intenção deste artigo abordar questões relacionadas às teorias grupalistas, como também não é esse o enfoque do módulo, pois tais teorias são contempladas em outros 
momentos da formação desses estudantes. O importante é destacar que este artigo aposta em referenciais teóricos que abordam experiências de práticas coletivas, evidenciando os aspectos de vivência nos grupos, de deslocamentos dos papéis conhecidos nos aqui mencionados espaços de atuação.

Ao abordar os temas da educação e da promoção da saúde, tem-se a finalidade de reforçar os conceitos mais amplos destes dois campos e questionar a ideia de que suas práticas de saúde não se limitam a identificar os efeitos nocivos de determinados comportamentos e hábitos, assim atuando sobre os indivíduos mais expostos ao risco, normatizando seus estilos de vida. Muitas dessas visões vêm sendo historicamente construídas e se valem de conceitos clássicos, que orientam a produção do conhecimento na área de saúde, especialmente da medicina. Neste trabalho, as críticas às posições circunscritas ao universo da prescrição e das normas desejam apoiar posições inclusivas, dialógicas, que propiciem a autonomia e a implicação na tomada de decisões (MENDES; FERNANDEZ; SACARDO, 2016).

Sob essa perspectiva, pode-se reafirmar que não é possível referir-se à autonomia como um processo de escolhas unicamente individuais, onde cada um exerce seu próprio desejo, a partir de suas necessidades próprias, com absoluta independência. A autonomia é, pois, uma condição que se constrói na relação com o outro, ou seja, socialmente. Vale dizer que a construção da autonomia se dá no plano individual e coletivo, e penetra na questão da constituição do sujeito na sua relação com o outro (CASTORIADIS, 1991). Reconhecer a autonomia como a ação de um sujeito que, como tal, é totalmente afetado e implicado no mundo e com outros, coloca uma série de desafios às práticas educativas e promotoras de saúde e, sobretudo, dá destaque a sua dimensão ética e política.

Não há como pensar a experiência do trabalho em equipe e com grupos sem considerar as questões éticas ali envolvidas. Os diferentes dilemas, colocados cotidianamente pela ação do cuidado e da promoção de saúde são debatidos no módulo a partir das posturas, dos modos de agir e pensar presentes na constituição da equipe de docentes, de estudantes e do trabalho realizado com os grupos populacionais.

Entende-se que esta é uma das experiências marcantes da formação, já que o estudante se vê diante de uma nova postura ao trabalhar em equipe. Ele assume uma responsabilidade para com o grupo populacional acompanhado, e também aprende a lidar com a frustração, quando sente que não conseguiu realizar as atividades como era esperado.

No módulo, foram utilizadas três ferramentas pedagógicas, que se complementam e trazem as dimensões coletivas e individuais da experiência: o plano de ação, o livro da experiência e o diário de campo. A tarefa de construir um plano de ação exige dos estudantes uma capacidade de rever, reformular e readequar as ações durante todo o processo de intervenção.

$\mathrm{Na}$ sua elaboração, os estudantes são convocados a trabalhar com sensibilidade e protagonismo, a fim de escolherem temas e atividades mais interessantes para cada grupo acompanhado.

O livro da experiência é uma proposta inspirada em uma das técnicas da Pedagogia Freinet, com perspectiva interdisciplinar: 0 'livro da vida'. Nele, os estudantes, ao relatarem experiências do seu dia a dia, expressam suas memórias e retratam diferentes formas de perceber a aula e a vida (FREINET, 1975). O livro é coletivo e o registro pode ocorrer de diversas maneiras: com desenhos, escrita, colagens ou outra forma que a equipe inventar. Com mais esta ferramenta, a equipe de estudantes consegue acompanhar seus próprios tempos na experiência, observando as mudanças de ritmo - aceleração, desaceleração - ao longo das atividades, bem como os momentos de silêncio e de permanência, que permitem perceber as sutilezas que não surgem aos olhos de maneira imediata.

Os diários de campo servem para que 
os estudantes, após cada visita, anotem suas impressões a respeito dos encontros, descrevendo o que viram e ouviram; como a experiência os afeta; quais os momentos marcantes; que elementos - como o cheiro, o som e as cores do cenário - chamam mais a sua atenção. Deste modo, os estudantes vão, pouco a pouco, tomando posse de sua capacidade de pensar e construir atividades em grupo, conquistando a tão esperada autonomia. Esta é uma aposta que se desvia daquela defendida pela tradição acadêmica, que considera o aluno passivo em seu processo de aprendizado.

A conquista dessa autonomia pelo grupo de estudantes é somada ao modo como eles percebem a população com necessidades de saúde com a qual estão trabalhando. Esta postura dos estudantes diz respeito a uma atitude ética, que permite compreender o que é bom e ruim para cada caso particular, sem impor regras de conduta, sem partir de diagnósticos prévios ou de uma ideia de saúde que se limita à cura de doenças.

$\mathrm{Na}$ esteira de filósofos como Baruch de Espinosa e Gilles Deleuze, este trabalho ressalta que existe diferença entre uma atitude ética e uma atitude moral, no campo da saúde. Espinosa (2007) e Deleuze (2002) ajudam a pensar no campo da saúde e da formação acadêmica, a partir do plano dos encontros. Antes de partir de regras anteriores aos encontros, que decidem o que é correto ou incorreto para a efetuação de um cuidado, considera-se o que é um bom e um mau encontro em saúde, para cada situação. Neste sentido, as prescrições, os diagnósticos produzidos fora do momento do encontro, levam a uma postura moral, pautada em deveres que valem para todos, independentemente das situações singulares.

A promoção de saúde não está definida previamente. É preciso conhecer o que são os bons e maus encontros, para aqueles que a vivem. Bons encontros são aqueles que fortalecem alguém, ou seja, que lhe trazem alegria, que lhe agradam, que se compõem com seu estado atual; e maus encontros são aqueles que enfraquecem alguém, que lhe trazem tristeza, que lhe desagradam, que não convêm com sua experiência atual (DELEUZE, 2002)

A experiência indica que não são sempre os mesmos alimentos, as mesmas pessoas ou as mesmas situações que fazem bem ou mal a alguém, tudo depende do estado em que esta pessoa se encontra no momento. Por isso, promover saúde implica em considerar, também, de que modo um indivíduo ou grupo se apresenta na experiência e que situações podem lhe fortalecer.

As ferramentas pedagógicas auxiliam os alunos nesse aprendizado. Suas anotações e percepções ajudam a perceber quais são seus incômodos, de que maneira participam da equipe e são afetados por aqueles com quem trabalham. Muitas vezes, eles veem e escutam coisas grandes demais, o que lhes exige um tempo de reflexão sobre a própria experiência. Neste sentido, diz-se que a equipe de estudantes está em contínuo processo de reinvenção, pois os acordos iniciais precisam ser revistos e avaliados; a escuta, afinada; as atividades, modificadas, de acordo com os acontecimentos novos que surgem no processo.

Ressaltam-se, abaixo, algumas questões produzidas e indicadas nas avaliações feitas pelos estudantes que experienciam essa modalidade formativa.

\section{Os efeitos da formação comum}

A formação comum é desafiadora, pois ninguém está previamente preparado para ela. O convite ao aprendizado coletivo acontece desde o diálogo entre os docentes de áreas distintas, e junto aos estudantes organizados em turmas mistas. Além disso, o deslocamento para o campo, ou seja, a saída da universidade implica em aprender a agir e pensar no cenário dos serviços e da população atendida, 
que se constitui segundo regras, funcionamento e demandas próprias.

A partir da avaliação que os estudantes realizaram, a respeito da experiência, foram encontrados pontos marcantes e decisivos para a formação, além do que eles apontaram como dificuldades e que poderia ser modificado. Sendo o aprendizado pautado na experiência um dos pilares desta formação, coloca-se em debate a existência de uma inter-relação entre teoria e prática, a relação de parceria de trabalho comum entre os atores deste processo e de autonomia de todos os envolvidos. Em algumas falas dos estudantes, pode-se perceber situações que eles valorizam e/ou produzem tensões no aprendizado coletivo.

Um dos pontos valorizados é o fato de a experiência permitir estabelecer contato com diferentes populações em suas situações singulares de vida e condições de saúde:

A possibilidade que a experiência nos passa quanto à importância da colaboração com o próximo dentro do modelo de saúde.

A interação e troca de experiências e sentimentos de pessoas com vidas tão distantes.

Um dos estudantes ainda pontua o quanto é gratificante perceber que o bom vínculo com o grupo populacional produz efeitos neste trabalho:

A maior experiência foi poder deixar os usuários em momentos descontraídos, dinâmicos, e poder ouvir deles a consideração e o laço de carinho que se formaram com os estudantes.

Além dessa leitura sobre a experiência do módulo, aparecem outros apontamentos de estudantes, que questionam as dificuldades enfrentadas ao longo do semestre. Enquanto para alguns estudantes e docentes o deslocamento dos saberes conhecidos e o encontro com o imprevisto aparecem como algo enriquecedor, segundo as falas acima; para outros, o modelo tutelar de educação é ainda defendido. Alguns estudantes e docentes consideram precoce a experiência de campo no segundo ano de formação, justificando-se mediante uma possível falta de capacidade, de preparação e maturidade dos estudantes. Esta leitura parece se pautar em uma concepção, que compreende a teoria como anterior à prática, considerando o momento do debate teórico como preparador para a ação em campo, como pode ser visto nestas falas:

O trabalho em grupo deve ser trabalhado mais em teoria, para depois ir para campo. Quando chegamos em campo ficamos perdidos no que deve ser feito.

Falta aplicar mais os textos na prática.

Diferentemente dessa leitura, a perspectiva que o módulo incorpora é de que teoria e prática são dois campos intrinsecamente implicados, de maneira que ambos acontecem em sala de aula e na experiência de campo. Teoria e prática são componentes de uma só unidade, sendo simultaneamente autônomas e dependentes entre si (VASQUEZ, 1977). A teoria não é, pois, concebida como um conhecimento a ser aplicado.

Colocar em análise a separação entre teoria e prática, sendo aquela pré-condição para esta, é tentar romper com o lugar autoritário do discurso competente. A produção dos especialistas, daqueles que detêm o saber, que são preparados para prescrever algo para o outro, está diretamente relacionada a um discurso de dominação. Nesta lógica, aquele que não é especialista não pode decidir sobre sua própria vida, ou seja, é desautorizado do seu saber (CHAUI, 2014). No entanto, pela fala do estudante, o que se percebe é que esta discussão precisa de muito tempo para ser digerida, pois a utilização do texto da autora 'Contra o discurso competente', debatido em aula, parece apenas iniciar este questionamento. Pode-se dizer que as diferentes perspectivas quanto à relação entre teoria e prática também se conectam na maneira de conduzir as aulas e a formação. 
Acontece, algumas vezes, de o docente assumir a condução e a organização da equipe de estudantes, quando eles não conseguem organizar as atividades práticas ou não conseguem estabelecer diálogos dentro da equipe. Mesmo que o docente valorize a experiência de aprendizado dos estudantes como afirmação e superação de dificuldades, sente-se responsável pela boa condução da experiência e corre o risco de impedir que o estudante aprenda com esses obstáculos próprios ao processo. É o que uma das estudantes relata:

[...] não estamos tendo muito espaço para fazermos tudo o que queremos, havendo muita interferência do professor, tanto na decisão do que fazer, quanto na prática. Isso nos deixa inibidos, e tira a nossa chance de aprender a tomar decisões e a coordenar um grupo.

Qual a medida da intervenção de um docente para com seus estudantes? Esta é uma questão que permeia este trabalho de formação de equipes e de grupos. O docente também precisa lidar com o tempo de desencontro da equipe de estudantes, acompanhar o aprendizado lento e as frustrações vindas da condição imponderável das ações. As queixas dos estudantes quanto à dificuldade de trabalho em grupo aparecem com frequência e parecem ser um analisador do desafio de realizar um trabalho comum e conquistar uma autonomia, desde este momento de formação.

Alguns estudantes argumentam que, se a experiência não deu certo, isto se deve a uma falta de sorte com o grupo populacional escolhido ou com os colegas de equipe, que não eram os mais dedicados. Entende-se que estas leituras, que culpabilizam os grupos pelo fracasso de uma experiência, podem se aproximar do que se percebe como uma postura moral, que julga a experiência a partir de um modelo. Em uma das falas, que indica a incompatibilidade do trabalho em grupo, nota-se este movimento:

O trabalho pressupõe uma construção em grupo, colaborativa, que pouco ocorre. Alguns se responsabilizam demais, outros de menos. Não adianta propor um método de avaliação em grupo, quando as responsabilidades caem mais nas costas de alguns. O grupo não ocorre simplesmente jogando alunos em uma mesma sala, definindo uma tarefa. Precisamos ser mais realistas!

É interessante o clamor por 'realismo' expressado nessa fala. $\mathrm{O}$ estudante entende que, para formar uma equipe, não basta juntar aleatoriamente colegas que ainda não se conhecem, pois não é garantido que se estabeleça vínculo entre eles. No entanto, é justamente este o desafio colocado: Como construir um trabalho comum entre as pessoas presentes? Aposta-se na descoberta das relações de composição de uma equipe, e entre essa equipe e o grupo populacional. Observa-se, pela experiência do módulo, que, algumas vezes se estabelece um bom encontro entre a equipe e o grupo populacional, e, outras vezes ocorrem experiências ruins. No entanto, isto não quer dizer que tais relações não deram certo.

O aprendizado para lidar com os conflitos e as opiniões divergentes envolve diretamente a figura do docente supervisor nesse processo. O espaço da supervisão permite debater as particularidades de cada grupo, suas dificuldades e capacidades. No entanto, parece que são muitas as questões que demandam tempo de supervisão, de modo que nem todas podem ser contempladas. Como dizem alguns estudantes, há:

Poucas supervisões, carregamento psicológico muito alto.

Pouco tempo de módulo, para ter mais supervisão e mais planejamento.

Maior tempo para o módulo, para potencializar a experiência e permitir mais supervisão.

Além disto, na fala de um dos monitores, também se pode perceber que: 
"Demonstraram-se cansados e desgastados, mas sentiam-se amparados pela supervisão e pelos colegas de grupo".

O momento da supervisão é sempre um desafio para os docentes. O modo de supervisionar e conduzir as aulas depende sempre de seus conhecimentos prévios e da composição destes com a novidade da experiência. Além disso, cada turma inventa, com seu docente, um modo de conduzir a experiência, já que, de saída, ela não se pretende unilateral, e o protagonismo dos estudantes é convocado o tempo inteiro.

O que os supervisores parecem acolher são as queixas dos estudantes, que clamam por um cuidado frente ao processo intenso que vivem, mas também, em alguns momentos, demandam o retorno à condição mais passiva de aprendiz. As muitas demandas e enfrentamentos colocados nesta experiência, com situações reais e com imprevistos contínuos, às vezes aparecem como algo grande demais para eles. É o que pode ser percebido em algumas falas, quando os estudantes se queixam da falta de energia para realizar as atividades e também de não haver condições mínimas de trabalho, como espaço disponível nos serviços:

[...] que a estrutura do local não seja adequada para receber os alunos, não ter uma sala fica difícil. Seria legal, sim, em novas alternativas.

Outro estudante salienta que há uma dificuldade de diálogo com os profissionais do serviço: "Dificuldade de interação com as agentes de saúde".

Estas falas dos estudantes indicam que o módulo se ocupa, de fato, de uma experiência real e não de uma situação simulada. Tais dificuldades, inerentes a esta experiência, estão atravessadas também por outras demandas da formação, que exigem tempo de dedicação, como relata este estudante: " $A$ falta de tempo para se planejar não permite aproveitar, no módulo, tudo que poderia ser aproveitado".

\section{Conclusões}

A partir da análise da experiência de um módulo curricular, em uma formação em saúde, através dos textos de apoio, do referencial teórico-metodológico e das avaliações dos estudantes, pode-se pensar o quão desafiador é produzir experiências interdisciplinares e interprofissionais, ao longo do processo formativo.

Quando se deixa o campo do discurso, quanto à importância da perspectiva interdisciplinar e do trabalho comum, e se considera a experiência prática da preparação e efetivação de um módulo da formação, percebe-se que os lugares conhecidos do docente e do estudante são colocados em análise.

Entende-se que, nesse modo de formar profissionais de saúde, a busca pela autonomia no processo formativo é decisiva. Para tanto, há um trabalho de negociação e aprendizado no diálogo, e preparação das atividades com docentes na produção comum do cuidado.

Uma experiência, para ser interdisciplinar e comum, envolve a questão do cuidado de docentes e estudantes, que demandam um espaço de reflexão coletiva que os ajude a sair da normatização, própria à lógica acadêmica. Tal lógica implica cumprir um determinado número de aulas e atividades previstas, contando com resultados satisfatórios no trabalho da equipe de estudantes com o grupo populacional. Muitas vezes, as equipes não criam vínculos, se frustram com o resultado do trabalho realizado. No entanto, estes supostos 'erros' ensinam a lidar com a realidade, em seus diversos tempos de encontros.

Este trabalho implica em colocar em análise, o tempo todo, a condição ética da experiência, as expectativas, os limites de um grupo, os modos de reinventar atuações que historicamente têm sido individualistas e corporativas, afastando, cada vez mais, as áreas profissionais, na medida em que se busca afirmar a identidade e a especificidade de cada uma delas. 
Entende-se que a singularidade dessa experiência vivida em uma universidade pública, que vem tentando construir uma formação interdisciplinar e comum, aparece como um exemplo que pode apresentar pistas a outras experiências. As dificuldades vividas no campo da formação em saúde e as diversas tentativas de criar experiências comuns, desde os primeiros anos de graduação, é um desafio que tem convocado estudantes e docentes à invenção e ao deslocamento dos lugares conhecidos. O trabalho de pactuação entre docentes, de preparação do conteúdo programático e dos campos onde são realizadas as atividades tem se mostrado instigante. A tentativa a ser empreendida é a de lutar contra a burocratização das ações e do modo de pensar a saúde, para que a experiência seja um aprendizado criativo e produtor de sujeitos eticamente compromissados com a vida.

\section{Colaboradores}

Todos os autores contribuíram igualmente para a produção e revisão do artigo.

\section{Referências}

AYRES, J. R. C. M. Sujeito, intersubjetividade e práticas de saúde. Ciência \&t Saúde Coletiva, Rio de Janeiro, v. 6, n. 1, p. 63-72, 2001.

BARROS, R. B. Grupo: a afirmação de um simulacro. Porto Alegre: UFRGS, 2007.

BRASIL. Ministério da Saúde. Curso de Formação de Facilitadores de Educação Permanente em Saúde. Rio de Janeiro: Fiocruz, 2005. Disponível em: <http://bvsms. saude.gov.br/bvs/publicacoes/curso_facilitadores_unidade_trabalho.pdf>. Acesso em: 20 maio 2016.

CASTORIADIS, C. $A$ instituição imaginária da sociedade. 3. ed. Rio de Janeiro: Paz e Terra, 1991.

CHAUÍ, M. S. Contra o discurso competente. In: ROCHA, A. A ideologia da competência. Belo Horizonte: Autêntica, 2014. p. 113-119.

CZERESNIA, D. O conceito de saúde e a diferença entre promoção e prevenção. In: CZERESNIA, D.; FREITAS, C. M. (Org.). Promoção da Saúde: conceitos, reflexões, tendências. Rio de Janeiro: Fiocruz, 2003. p. 39-53.

DELEUZE, G. Espinosa: filosofia prática. São Paulo: Escuta, 2002.

FEUERWERKER, L. C. M.; CAPOZZOLO, A. A. Mudanças na formação dos profissionais de saúde: alguns referenciais de partida do Eixo Trabalho em Saúde. In: CAPOZZOLO, A. A.; CASETTO, S. J.; HENZ, A. O. (Org.). Clínica comum: itinerários de uma formação em saúde. São Paulo: Hucitec, 2013, p. 35-58.

FREINET, C. As técnicas Freinet da Escola Moderna. Lisboa: Estampa, 1975.

FREIRE, P. Pedagogia da autonomia: saberes necessários à prática educativa. Rio de Janeiro: Paz e Terra, 2008. 
FURTADO, J. P. Equipes de referência: arranjo institucional para potencializar a colaboração entre disciplinas e profissões. Interface - Comunicação, Saúde, Educação, Botucatu, v. 11, n. 22, p. 239-255, maio/ago. 2007.

HENZ, A. O. et al. Trabalho entreprofissional: acerca do comum e a cerca do específico. In: CAPOZZOLO, A. A.; CASETTO, S. J.; HENZ, A. O. (Org.). Clínica comum: itinerários de uma formação em saúde. São Paulo: Hucitec, 2013. p. 163-186.

KASTRUP, V.; PASSOS, E. Cartografar é traçar um plano comum. In: PASSOS, E.; KASTRUP, V.; TEDESCO, S. (Org.). Pistas do método da cartografia: a experiência da pesquisa e o plano comum. Porto Alegre: Sulina, 2014. p. 15-41.

LOURAU, R. René Lourau na UERJ: análise institucional e práticas de pesquisa. Rio de Janeiro: UERJ, 1993.
MENDES, R.; FERNANDEZ, J. C. A.; SACARDO, D. P. Promoção da saúde e participação: abordagens e indagações. Saúde em Debate, Rio de Janeiro, v. 40, n. 108, p. 188-201, jan./mar. 2016.

NANCY, J. L. La Comunidad Inoperante. Santiago de Chile: LOM/Arcis, 2000.

SPINOZA, B. Ética. Belo Horizonte: Autêntica, 2007.

VASQUEZ, A. S. Filosofia da práxis. 2. ed. Rio de Janeiro: Paz e Terra, 1977.

Recebido para publicação em agosto de 2016

Versão final em março de 2017

Conflito de interesses: inexistente

Suporte financeiro: suporte financeiro através de pagamento de Bolsas, do Programa Institucional de Bolsas de Monitoria 2014-2015 da Unifesp, aos alunos monitores do Eixo Trabalho em Saúde que foram responsáveis pela aplicação do instrumento de avaliação do Módulo que está em discussão neste artigo 